\title{
The Child PTSD Symptom Scale in Abused Children: Criteria for Diagnosis
}

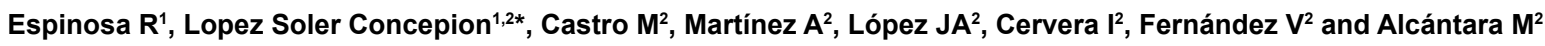

${ }^{1}$ University Hospital V. Arrixaca, Madrid-Cartagena, s/n, 30120 El Palmar, Murcia, Spain

${ }^{2}$ University of Murcia, Campus Universitario, 11, 30100 Murcia, Spain

\begin{abstract}
By analyzing the psychometric properties of the Child PTSD Symptom Scale (CPSS) this study aims to provide data for improving the diagnostic criteria of PTSD in childhood and adolescence. The sample consists of 221 children aged between 8 and 17, who have suffered chronic intrafamily abuse. The factor structure, reliability and concurrent and discriminant validity of the CPSS scale have been analyzed. The exploratory factor analysis supported a single factor in contrast to the three and four factor structure proposed in DSM-IV and DSM-5. Internal consistency was high (alpha $=0.884$ ), and concurrent and discriminant validity tests were also significant.
\end{abstract}

Keywords: PTSD, Diagnosis criteria; Child abuse; Child PTSD symptom Scale; Exploratory factor analysis

\section{Introduction}

The study of risk factors and specifically exposure to interpersonal violence has been linked to posttraumatic stress in childhood and adolescence [1-3]. Chronically traumatized children also show signs of PTSD, as well as other associated psychological disorders such as Attention Deficit Disorder and Hyperactivity, major depression, dissociative disorders, behavioral disorders, oppositional defiant disorder, anxiety disorders [4-6] eating disorders, and alcohol and substance abuse $[7,8]$. They also show greater incidence of smoking, compulsive and purgative behaviors [9].

If we compare studies carried out on the adult population about PTSD, only a few have examined PTSD and the symptom structure in samples of children and adolescents [10-13]. Research suggests that many children with PTSD are underdiagnosed $[14,15]$ and that the criteria used for adults are inappropriate for children. Some studies on post-traumatic reactions have consistently shown that many people with subclinical PTSD symptoms are affected and have significant dysfunction [16-18]. In the absence of an adequate PTSD diagnosis particularly in children, a line of research has been developed on the alternative or partial diagnosis of PTSD [19-25] which might be due to the post-traumatic development of symptoms that do not reach the required APA diagnostic threshold, although they appear to be the most appropriate for diagnosis in childhood.

In this line of establishing alternative criteria that improve recognition and diagnosis of PTSD in childhood [26,27] established the presence and severity of PTSD according to the number of symptoms without needing to belong to a specific symptomatic group. performed a review of research on PTSD symptomatology and diagnostic criteria in childhood and adolescence, and proposed new algorithms on an empirical basis that have been partially accepted by APA (DSM-5) for pre-school children, proposed new algorithms on an empirical basis that have been partially accepted by APA (DSM-5) for pre-school children. In the DSM-5, children aged 6 to 18 are assessed with the same PTSD diagnostic criteria as adults.

The latest APA classification, DSM-5, has modified the criteria and increased diagnostic sensitivity for preschoolers ( $0-6$ years). These changes show advantages for 6 year old children and disadvantages for those above this age, since it requires four groups of symptoms: reexperiencing, avoidance, hyperarousal and alterations in cognitions and mood, by replacing the three-factor DSM-IV model where these latter symptoms did not appear. These new criteria may increase inadequacy of diagnosis in childhood and adolescence by modifying the diagnostic algorithm that includes another group of symptoms. The classification criteria included in DSM-5 have provided answers in preschool children from 0 to 6 years of age, greatly improving diagnostic sensitivity by decreasing the number of necessary avoidance symptoms in DSM-IVTR that were three but are now reduced to one, but further research on children above 6 years of age should still be carried out to establish manifestations of PTSD symptoms and other posttraumatic reactions such as complex trauma. Thus, there remains some controversy regarding the symptomatic patterns that comprise PTSD in childhood and adolescence [28], and there have been increasing empirical studies on the latent PTSD structure to find the most appropriate structure [29-31] specifically described the relevance of this line of research by highlighting that the procedure enables recognizing the major clusters that make up posttraumatic stress disorder, the subsets of resulting PTSD symptoms have implications for diagnostic algorithms. Exploratory factor analysis can help identify the correct amount and composition of PTSD symptom sets and, therefore, establish the correct diagnostic PTSD algorithm. The aim of these studies, besides validating the PTSD diagnostic criteria, is to improve knowledge about the etiology and maintenance of post-traumatic stress disorder and to allow the application of specific treatments [32-34].

Before the forthcoming appearance of ICD-11 and the recent publication of DSM-5, many authors have analyzed the pros and cons of both classification systems. If, on the one hand, there is a deserved space for PTSD in children under 6 years of age in the DSM-5 [34] on the other hand, shows the complexity and comorbidity present in the APA system and suggests trying a simpler approach to diagnosis which can be used in non-English speaking countries and with minimal resources. Initially six symptoms are proposed that include re-experiencing the traumatic event, accompanied by fear or terror;

*Corresponding author: Lopez Soler Concepion, Department of Psychological Personality, Evaluation and Treatment, University of Muricia, Calle Campus Universitario, 11, 30100 Murcia, Spain, Tel: 968-364117; E-mail: clopezs@um.es

Received January 01, 2018; Accepted February 01, 2018; Published February 10,2018

Citation: Espinosa R, Concepion LS, Castro M, Martínez A, López, JA, et al. (2018) The Child PTSD Symptom Scale in Abused Children: Criteria for Diagnosis. J Ment Disord Treat 4: 154. doi:10.4172/2471-271X.1000154

Copyright: (c) 2018 Espinosa R, et al. This is an open-access article distributed under the terms of the Creative Commons Attribution License, which permits unrestricted use, distribution, and reproduction in any medium, provided the original author and source are credited. 
avoidance of traumatic memories; and a feeling of actual threat manifested by excessive hypervigilance or a startle reaction increase, this proposal is compatible with that incorporated into the DSM- 5 for children of 6 years and under. Previous study [35] provides preliminary evidence of the validity of the ICD-11 proposal for diagnoses of PTSD and complex post-traumatic stress disorder.

Factor analysis studies about the PTSD symptom structure in childhood and adolescence showed that models with the greatest adjustment show a lower number of factors in children than in the traumatized adult population [36-39] although some studies do not confirm this, such as the TSCC-SF confirmatory factor analysis (A short form of the Trauma Symptom Checklist for Children) supporting a model of 6 Factors: Anger, PTSD, Dissociation, Sexual Concerns, Suicidal Depression, and Anxiety [40]. Many of the differences could be due to the measurement instrument particularly the number of items and their nature, when the test includes symptoms of anxiety, depression, sexual abuse and other facets, the number of factors may increase. However, these could be specific symptoms of complex trauma and not of PTSD symptoms [41,42].

They performed a study on a sample of 206 adolescent school children (6th-12th graders) in Mississippi, USA. The mean age was 14.46 years $(\mathrm{SD}=1.91)$ age range 11 and 18 years. The EFA and CFA supported a single-factor structure, in contrast to the three-factor model. Scores comprising this one-factor structure were also associated with high reliability $(\alpha=0.93)$, and concurrent and discriminant validity coefficients were also found to be strong. It is observed that the higher the age of the samples studied, military veterans [43-45] adults in active military service during the Gulf War [46], with average age above 32 years $[47,48]$ the number of latent factors increases and when the age (children and adolescents) of the sample is lower, the number of factors is decreased [49,50]. The decrease in the number of symptomatic groups in children is consistent with the new proposal of diagnostic criteria for children up to 6 years of age in the DSM-5, based on studies by Sheeringa in preschoolers.

In this study, we intend to explore the factor structure of PTSD symptomatology in the children and adolescent population who have suffered severe and chronic traumatic experiences, in order to observe whether the symptomatic groups proposed by APA show empirical validity and provide better diagnostic criteria in PTSD in childhood and adolescence.

\section{Method}

\section{Participants}

The total sample consisted of 221 children aged between 8 and 17, of whom 109 (49.3\%) were boys and 112 (50.7\%) girls, who had suffered chronic intra-family mistreatment by their attachment figures. The study was carried out with two groups of abused minors. The first was made up of 68 children in care from the Region of Murcia due to their parents having lost custody of their children, who were assigned to the Project of Evaluation, Diagnosis and Psychological Intervention for CIC, with a mean age of $11.80(\mathrm{SD}=2.38), 51.2 \%$ boys and $48 \%$ girls. Fifty per cent of the minors in care lived in the shelter, $37.2 \%$ in care with extended family, and $12.8 \%$ were with a foster family, $84.9 \%$ of the children in care were Spanish. For $11.5 \%$ of the children only the father was alive and for $24.4 \%$ only the mother, $64.1 \%$ had both parents alive, $10.5 \%$ of fathers, $28.1 \%$ of mothers and $8.8 \%$ of both parents, had some mental illness. $25.6 \%$ of fathers, $10.5 \%$ of mothers and $17.4 \%$ of both parents habitually consumed substances. $9.3 \%$ of fathers and $1.2 \%$ of mothers had been incarcerated at some time.
The second group comprised 153 children, with severe psychological disturbances, who had been exposed to intimate partner violence (IPV), these children were living at the time with their biological family, specifically their mother in many cases, and had been assigned to the Psychological Intervention for Child Intimate Violence Victims Service. The age range of the children in this subsample was 8 to 17 years $(M=11.50, S D=2.72) ; 49.7 \%$ were boys and $50.3 \%$ girls. No significant differences were found in age among boys and girls from the total group, $\mathrm{t}(219)=0.842, \mathrm{p}=0.401$. The mothers' ages ranged from 25 to 53 years $(\mathrm{M}=37.7 ; \mathrm{SD}=5.4)$ and $86.2 \%$ were Spanish nationals. Of the 139 mothers, $5.4 \%$ had no education, $50.5 \%$ Primary education, $37 \%$ Secondary education, and $7.1 \%$ University education. In $99.5 \%$ of cases the aggressor was the biological father of the child. Participants came from urban and suburban areas of the Region of Murcia (Spain). At the time of registration for this study, most of the mothers (92.1\%) did not live with the aggressor of both the child and the mother, and $26.8 \%$ had a stable partner. In most cases $(68.2 \%)$ the children only lived with their mother, $13.8 \%$ lived with their mother and other relatives, $10.1 \%$ lived with their mother and a stable partner, and 7.9\% lived with their mother and the aggressor.

\section{Procedure}

The children were referred to specialist assessment and psychological intervention services as they presented serious behavioral and/or emotional and/or adaptation problems. All were treated following WHO and Helsinki Treaty recommendations. First, an interview was carried out and then the areas that were considered affected were explored clinically and psychometrically, as well as the children's competencies and skills in personal resilience. In all cases, informed consent was obtained from legal guardians.

\section{Measures}

The Child PTSD Symptom Scale (CPSS) is an instrument developed to assess the presence of symptoms of posttraumatic stress disorder in children and adolescents from 8 to 18 years of age. It is based on the diagnostic criteria for post-traumatic stress disorder of DSM-IV and DSM-IV-TR. It comprises 17 Likert-type items referred to the frequency of manifestation of symptoms, Re-experiencing (5 items), Avoidance ( 7 items) and Hyperarousal (5 items), and 7 items that assess functional deterioration.

The psychometric properties of the original version of CPSS show acceptable levels of internal consistency, presenting Cronbach's alpha coefficients of 0.89 for the total scale, 0.80 for Re-experiencing, 0.73 for Avoidance, and 0.70 for Hyperarousal. The test-retest reliability of scores was 0.84 for the total scale, 0.85 for the Re-experiencing subscale, 0.63 for the Avoidance subscale, and 0.76 for the Hyperarousal subscale. The CPSS presents excellent psychometric properties on the English and Spanish versions, excellent internal consistency was seen in both versions (Spanish version: $\alpha=0.88$ and English version: $\alpha=0.89$ ). Internal consistency was moderately good in subscales ( $\mathrm{Re}$ experiencing, Avoidance, Hyperarousal) for both versions, range 71-84. Previous research confirmed that CPSS for English-speaking children and adolescents with organic lesions shows reliable measures and construct validity that can be extended to findings with Latin children and adolescents. The coefficient of the global scale of Cronbach's $\alpha$ in the Latin immigrant population was

The Children's Impact of Traumatic Events Scale (CITES-R) [51]. The CITES-R is a 78-item clinician-administered scale developed to assess the effects of sexual abuse and other abuses on young people 
between the ages of 8 and 16 years old. Items are rated on a 3-point Likert scale ("not true", "somewhat true", "very true"). The CITES-R is comprised of 4 main scales and 11 subscales: (1) PTSD (Intrusive Thoughts, Avoidance, Hyperarousal, and Sexual Anxiety); (2) Social Reactions (Negative Reactions from Others and Social Support); (3) Abuse Attributions (Self-Blame and Guilt, Empowerment, Personal Vulnerability, and Dangerous World); and (4) Eroticism. For this study, Re-experiencing, Avoidance and Hyperarousal subscales have been used. The internal consistency of the whole scale was good with an alpha value of 0.89 [51]. High levels of reliability for the PTSD scale were also reported, ranging from an alpha value of 0.88 to 0.89 [52] The Impact of Event Scale (IES) [53] is a 15 -item questionnaire that evaluates PTSD through Re-experiencing symptoms (7 items) and Avoidance (8 items). The authors had to reduce the number of items of the original scale from 20 to 15 as they were empirically clustered. Reliability was 0.86 . Cronbach's Alpha was also high: Re-experiencing 0.78 , Avoidance 0.82 and a correlation of $0.42(p>0.000)$ between both. Test-retest reliability was 0.87 for total measures and 0.89 for the intrusion subscale and 0.79 for the avoidance subscale.

The Traumatic Stress Disorder Scale of the Screen for Child Anxiety Related Emotional Disorders (SCARED), 4 trauma-specific items of The Pediatric Emotional Distress Scale (PEDS) [54]. The 21-item parentreport rating scale includes 17 general behavior items. Total scores were shown to have good internal consistency, and both test-retest and inter-rater reliability were at acceptable levels. Discriminant analyses demonstrated the PEDS could distinguish traumatic event exposure and non-exposure groups. Cronbach's alpha coefficients were 0.72 to 0.78 and for the total 17 items were 0.85 . The authors highlighted that correlations between items were adequate and that each contributed to the instrument satisfactorily. Test-retest reliability after examining 102 families was acceptable (from 0.55 to 0.61 ).

The Child Behavior Checklist is one of the most frequently used instruments in assessing the frequency and intensity of emotional/ behavioural problems in children and adolescents. It is composed of 113 items. The CBCL yields eight syndrome scales: AnxiousDepressed, Withdrawn-Depressed, Somatic Complaints, Social Problems, Thought Problems, Attention Problems, Rule-breaking Behaviour, and Aggressive Behaviour. The CBCL also offers internalizing problems by adding the scores for the syndromes of AnxiousDepressed, Withdrawn-Depressed, and Somatic Complaints, as well as another score for externalizing problems by adding the scores for the syndromes of Rule-Breaking Behaviour and Aggressive Behaviour. The CBCL has well-established reliability and validity [55]. With the current sample, the eight syndrome scales obtained alpha coefficients between 0.73 and 0.92 (Anxious-Depressed: $\alpha=0.82$; WithdrawnDepressed: $\alpha=0.77$; Somatic complaints: $\alpha=0.75$; Social problems: $\alpha=0.73$; Thought problems: $\alpha=0.80$; Attention problems: $\alpha=0.84$; Rulebreaking behaviour: $\alpha=0.74$; Aggressive behaviour: $\alpha=0.92$ ) .

\section{Data analysis}

To evaluate the structure of the CPSS scale, an analysis of items and a study of the operation of the categories of each were carried out. In addition, an exploratory factor analysis (EFA) was performed with the unweighted least squares method from the polychoric correlation matrix, and parallel analysis (PA) was used to determine the dimensional structure of the scale. The decision on the appropriate number of factors was taken using the GFI and RSMR statistics, where GFI must be greater than 0.95 and RMSR $<0.08$.

FACTOR Version 10 [56] was used to perform the exploratory factor analysis.

Score reliability was determined with the Cronbach's alpha coefficient; the concurrent validity through a study with a subsample of abused children in care described in results.

\section{Results \\ Descriptive statistics}

Table 1 presents the item analysis (Mean and SD) of the total scores in each category. In our case it is seen that the means of the total scores of the children who have selected each category increase in succession, indicating that this set of categories adequately represents the measurement of the attribute we wish to measure.

Contributions to the test by each item show correlations higher than 0.30 in all cases, between 0.64 (item 17) and 0.34 (item 8), revealing that all items obtained adequate values to measure the attribute.

\begin{tabular}{|c|c|c|c|c|c|c|c|c|c|}
\hline \multirow[t]{2}{*}{ Symptoms } & \multirow[t]{2}{*}{ Mean } & \multirow[t]{2}{*}{ SD } & \multirow[t]{2}{*}{ Skewness } & \multirow[t]{2}{*}{ Kurtosis } & \multirow[t]{2}{*}{$r_{j x}$} & \multicolumn{4}{|c|}{ Categories } \\
\hline & & & & & & 0 & 1 & 2 & 3 \\
\hline CPSS1 & 0.9 & 1.1 & 0.7 & -0.9 & 0.54 & $8.2(7.3)$ & $13.7(8.6)$ & $20.8(5.9)$ & $25.1(11.7)$ \\
\hline CPSS2 & 0.7 & 1.0 & 1.3 & 0.4 & 0.55 & $9.9(8.0)$ & $13.9(8.6)$ & $26.8(8.1)$ & $27.1(10.5)$ \\
\hline CPSS3 & 0.8 & 1.0 & 1.1 & -0.1 & 0.60 & $8.7(7.6)$ & $14.8(7.4)$ & $22.8(7.1)$ & $28.4(10.1)$ \\
\hline CPSS4 & 1.3 & 1.1 & 0.3 & -1.1 & 0.61 & $6.1(6.7)$ & $10.6(6.8)$ & $18.6(9.6)$ & $25.1(8.9)$ \\
\hline CPSS5 & 0.9 & 1.1 & 0.8 & -0.8 & 0.60 & $7.8(6.7)$ & $15.5(8.7)$ & $20.6(8.2)$ & $26.4(10.0)$ \\
\hline CPSS6 & 1.4 & 1.2 & 0.1 & -1.5 & 0.42 & $7.3(8.4)$ & $12.0(7.7)$ & $18.4(9.5)$ & $20.2(10.2)$ \\
\hline CPSS7 & 0.8 & 1.1 & 0.9 & -0.6 & 0.48 & $9.1(8.1)$ & $14.9(8.0)$ & $22.3(9.1)$ & $23.8(11.0)$ \\
\hline CPSS8 & 0.5 & 0.8 & 1.5 & 1.6 & 0.34 & $11.2(9.4)$ & $15.9(10.5)$ & $21.4(8.3)$ & $27.8(10.5)$ \\
\hline CPSS9 & 0.7 & 1.1 & 1.2 & -0.0 & 0.48 & $9.9(8.7)$ & $15.1(8.1)$ & $20.9(7.2)$ & $26.4(10.5)$ \\
\hline CPSS10 & 0.5 & 0.9 & 1.7 & 1.7 & 0.59 & $9.8(7.7)$ & $17.4(8.6)$ & $24.5(8.2)$ & $26.0(9.8)$ \\
\hline CPSS11 & 0.6 & 1.0 & 1.4 & 0.7 & 0.49 & $9.8(8.4)$ & $17.4(8.0)$ & $25.5(6.4)$ & $26.0(11.4)$ \\
\hline CPSS12 & 0.5 & 0.9 & 1.6 & 1.3 & 0.54 & $10.2(8.5)$ & $16.6(7.7)$ & $26.3(8.0)$ & $29.3(9.6)$ \\
\hline CPSS13 & 0.7 & 1.0 & 1.3 & 0.3 & 0.57 & $9.3(7.6)$ & $16.4(9.5)$ & $21.9(8.3)$ & $28.7(8.8)$ \\
\hline CPSS14 & 0.8 & 1.1 & 0.9 & -0.5 & 0.52 & $8.7(7.7)$ & $17.1(8.0)$ & $18.1(9.4)$ & $26.9(10.5)$ \\
\hline CPSS15 & 0.8 & 1.0 & 1.0 & -0.3 & 0.43 & $9.9(9.0)$ & $13.5(8.6)$ & $20.5(9.7)$ & $25.5(9.7)$ \\
\hline CPSS16 & 0.9 & 1.1 & 0.8 & -0.8 & 0.52 & $9.1(7.9)$ & $11.9(7.9)$ & $23.5(8.7)$ & $24.7(9.5)$ \\
\hline CPSS17 & 0.7 & 1.0 & 1.2 & 0.1 & 0.64 & $8.8(6.9)$ & $15.9(7.7)$ & $24.1(8.9)$ & $29.6(9.1)$ \\
\hline
\end{tabular}

Notes: $r_{\mathrm{j} x}=$ item-total corrected correlation. 


\section{Structural validity}

Since the Bartlett statistic was significant (Bartlett $=1156.8, \mathrm{df}=136$; $\mathrm{p}<0.001)$, and the Kaiser-Meyer-Olkin test was very good $(\mathrm{KMO}=0.91)$, EFA can be used appropriately.

Using the parallel analysis with 500 replicates, a unifactorial solution with a GFI $=0.98$ and a $\mathrm{RSMR}=0.07$ was obtained (Kelley Criteria $=0.067$ ); this factor also explained $47 \%$ of the total variance of the correlation matrix.

All items had significant factor loadings (Table 2) ranging from 0.76 (Startle response) to 0.43 (Amnesia), indicating that the structure of the CPSS scale is unidimensional in this population of abused children.

As for the internal consistency of the scale, the alpha coefficient was 0.93 , indicating a very high reliability of scores obtained with this post-traumatic stress scale.

\section{Empirical validity}

To obtain evidence of concurrent validity, a previous study was performed with some of the abused minors who make up this research $(\mathrm{N}=50)$, who were given the following scales: the Children's Impact of Traumatic Events scale (CITES-R) (SCARED-R) [57] and the Impact of Event Scale (IES) and CPSS.

In contrast to the other scales, the CPSS presented the highest internal consistency, both for the total scale $(\alpha=0.91)$, and for the Avoidance $(\alpha=0.81)$ and Hyperarousal $(\alpha=0.79)$ subscales. The CPSS obtained a significant correlation between re-experiencing and Avoidance subscales $(\mathrm{r}=0.678, \mathrm{p}<0.01)$, as well as between Avoidance and the same subscale of the CITES- $\mathrm{R}$ test $(\mathrm{r}=0.567)$ showing generally high correlations with the remaining subscales and symptomatic groups, indicating good concurrent validity (Table 2) [58-63].

Discriminant validity was analyzed by correlating CPSS scores with the Child Behavior Checklist (CBCL) subscales. The CPSS scores obtained low but significant correlations with the CBCL Anxiety subscales, $r=0.15, p=0.033$, and Somatic problems, $r=0.191, p=0.006$. However, correlations with Withdrawn-Depressed, $\mathrm{r}=0.061, \mathrm{p}=0.379$, Social Problems, $\mathrm{r}=0.112, \mathrm{p}=0.107$, Thought Problems, $\mathrm{r}=0.052$, $\mathrm{p}=0.458$, Attention Problems, $\mathrm{r}=0.028, \mathrm{p}=0.688$, Disruptive behaviors, $\mathrm{r}=0.084, \mathrm{p}=0.229$ and Aggressive behaviors, $\mathrm{r}=0.011, \mathrm{p}=0.877$, were low and not significant.
The correlation of the CPSS scale with age was very low, $r=0.06$, $\mathrm{p}=0.389$, showing that post-traumatic stress is not associated with the children's age [64-68]. On the other hand, significant differences were found regarding the sex of children in posttraumatic stress as measured by CPSS, $\mathrm{t}=-2.83, \mathrm{p}=0.005$, although the effect size was low, $\mathrm{d}=0.381$.

\section{Discussion and Conclusions}

The CPSS is an instrument with good psychometric characteristics, as shown by its use in different research, due to the speed of its application, reliable and valid results and adequate construct validity [69-72]. The internal consistency level was raised through the Cronbach alpha coefficient 0.884 , compared to the original values of Foa et al. [50] obtaining a consistency at global scale of 0.89 . In our study, item 8 , which had shown low consistency in other previously analyzed studies, contributes homogeneously together with the rest of the item with a correlation of 0.33 .

The results obtained in our study through EFA do not support the APA proposal of three or four symptomatic groups in PTSD diagnosis. Although the APA has reduced the number of PTSD symptoms for diagnosis in the preschool population, which is closer to our results, compared to the previous edition the number of symptoms has increased for those above this age [72-75]. Our empirical data point us toward a single factor in the line of Stewart, who after carrying out an Exploratory Factor Analysis and a Confirmatory Factor Analysis in a sample of school adolescents; found that factor loadings were directed towards a single factor, presenting a good adjustment index for the model.

The CFA and EFA supported a single-factor structure, contrary to the three-factor model. The scores comprising this single-factor structure were also associated with high reliability $(\alpha=0.93)$, and concurrent and discriminant validity tests were also found to be strong. The results may indicate that conglomerates of symptoms are not as relevant in childhood, and their use as diagnostic criteria may be significantly affecting the prevalence of PTSD in childhood and adolescence. Nevertheless, these results do not show us the cutoff point and number of symptoms needed to diagnose a child and/or adolescent with PTSD. The proposed WHO diagnostic criteria for ICD-11 may help in this task and allow a more adequate diagnosis of PTSD in childhood and adolescence [75-78].

\section{Items}

1. Having upsetting thoughts or images about the event when you didn't want to.

2. Having bad dreams or nightmares.

3. Acting or feeling as if the event was happening again.

4. Feeling upset when you think about or hear about the event.

5. Having feelings in your body when you think about or hear about the event.

6. Trying not to think about, talk about, or have feelings about the event.

7. Trying to avoid activities, people, or places that remind you of the traumatic event.

8. Not being able to remember an important part of the upsetting event.

9. Having much less interest in doing things you used to do.

10. Not feeling close to people around you.

11. Not being able to have strong feelings.

12. Feeling as if your future plans or hopes will not come true.

13. Having trouble falling or staying asleep.

14. Feeling irritable or having fits of anger.

15. Having troubleconcentrating.

16. Being overlycareful.

17. Being jumpy or easily startled.

\begin{tabular}{|c|c|}
\hline Factor loading & Communality $\mathbf{h}^{\mathbf{2}}$ \\
\hline 0.64 & 0.41 \\
\hline 0.65 & 0.42 \\
\hline 0.70 & 0.49 \\
\hline 0.68 & 0.46 \\
\hline 0.71 & 0.50 \\
\hline 0.49 & 0.24 \\
\hline 0.59 & 0.35 \\
\hline 0.43 & 0.18 \\
\hline 0.61 & 0.37 \\
\hline 0.74 & 0.55 \\
\hline 0.64 & 0.41 \\
\hline 0.67 & 0.45 \\
\hline 0.69 & 0.48 \\
\hline 0.63 & 0.40 \\
\hline 0.51 & 0.26 \\
\hline 0.60 & 0.36 \\
\hline 0.76 & 0.58 \\
\hline
\end{tabular}

Table 2: Unidimensional structure and factor loadings of the CPSS scale. 
The limitations of the study should be clarified. This study was based on the DSM-IV-TR criteria on which the CPSS is based, actually requiring a new version of the CPSS based on the DSM-5 criteria. An important limitation is the use of a clinical sample (as children were referred for presenting behavioral and/or emotional disorders secondary to intrafamily abuse) which also makes it difficult to generalize results to other populations as it cannot be contrasted with normal population data, unlike the APA. However, the study was able to contribute to a better knowledge of the psychometric properties of CPSS in population criteria that has suffered chronic intrafamily violence. Future research will continue to benefit from the CPSS properties but in different contexts (school, clinical, different communities). This research should focus attention on the appropriateness of the DSM- 5 criteria for the construction of self-reports that allow PTSD to be assessed more appropriately in children and adolescents.

\section{References}

1. Kataoka SH, Stein BD, Jaycox LH, Wong M, Escudero P, et al. (2003) A school-based mental health program for traumatized Latino immigrant children. Journal of the American Academy of Child y Adolescent Psychiatry 42: 311318.

2. Kataoka SH, Jaycox LH, Wong M, Nadeem E, Langley A, et al. (2011) Effects on School Outcomes in Low-Income Minority Youth: Preliminary Findings from a Community-Partnered Study of a School Trauma Intervention. Ethnicity \& Disease 21: 71-77.

3. Pynoos RS, Frederick C, Nader K, Arroyo W, Steinberg A (1987) Life threat and posttraumatic stress in school-age children. Archives of General Psychiatry 44: 1057-1063.

4. Alcántara MV, López-Soler C, Castro M, López JJ (2013) Psychological alterations in minors exposed to gender violence: Prevalence and differences of gender and age. Anales de Psicología 29: 741-747.

5. Kilpatrick DG, Ruggiero KJ, Acierno R, Saunders BE, Resnick HS (2003) Violence and risk of PTSD, major depression, substance abuse/dependence, and comorbidity: results from the National Survey of Adolescents. Journal of consulting and clinical psychology.71: 692-695.

6. Perry BD, Azad I (1999) Post-traumatic stress disorder in children and adolescents. Opiniones actuales en Pediatría 11: 121-132.

7. Dube SR, Felitti VJ, Dong M, Giles WH, Anda RF (2003) The impact of adverse childhood experiences on health problems: evidence from four birth cohorts dating back to 1900 . American Journal of Preventive Medicine 37: 268-277.

8. Hall CA, Henderson CM (1996) Cognitive processing therapy for chronic PTSD from childhood sexual abuse: A case study. Counselling Psychology Quarterly 9: 359-371.

9. Díaz A, Simatov E, Rickert V (2000) The independent and combined effects of physical and sexual abuse on health: Results of a national survey. Journal of Pediatric and Adolescent Gynecology 13: 89

10. Ayer LA, Cisler JM, Danielson CK, Amstadter AB, Saunders BE (2011) Adolescent posttraumatic stress disorder: An examination of factor structure reliability in two national samples. Journal of Anxiety Disorders 25: 411-421.

11. Chung MC, Jalal S, Khan NU (2014) Posttraumatic stress disorder and psychiatric comorbidity following the 2010 flood in Pakistan: Exposure characteristics, cognitive distortions, and emotional suppression Psychiatry 77 : 289-304

12. Stewart RW, Ebesutani C, Drescher CF, Young J (2015) The Child PTSD Symptom Scale: An Investigation of Its Psychometric Properties. Journal Interpersonal Violence.

13. Wang CW, Chan CLW, Ho RTH (2013) Prevalence and trajectory of psychopathology among child and adolescent survivors of disasters: a systematic review of epidemiological studies across 1987-2011. Social Psychiatry and Psychiatric Epidemiology 48: 1697.

14. Kendall-Tackett KA, Williams LM, Finkelhor D (1993) Impact of sexual abuse on children: A review and synthesis of recent empirical studies.

15. Makley A, Falcone R (2010) Posttraumatic stress disorder in the pediatric trauma patient. Seminars in Pediatric Surgery 19: 292-299.
16. Boyer BA, Kafkalas C, Tollen L, Swartz M (1999) A pilot study of posttraumatic stress in families with a pediatric spinal cord injury. Proceeding of the Society of Behavioral Medicines Twentieth Annual Meeting. Annals of behavioural Medicine.

17. Cohen E, Gadassi R (2009) Post-Traumatic Stress Disorder in young children exposed to terrorism: Validation of the alternative diagnostic criteria. Journal of Child and Adolescent Trauma 2: 229-224.

18. Hickling E, Blanchard E (1992) Post-traumatic stress disorder and motor vehicle accidents. Journal of Anxiety Disorders 6: 285-291.

19. Blanchard EB, Hickling EJ, Barton KA, Taylor AE, Loos WR, et al. (1994) One year prospective follow-up of motor vehicle accident victims. Behaviour Research and Therapy 34: 775-786.

20. Brancu M, Mann-Wrobel M, Beckham JC, Wagner HR, Elliott A (2016) Subthreshold posttraumatic stress disorder: A meta-analytic review of DSM-IV prevalence and a proposed DSM-5 approach to measurement. Psychological Trauma: Theory, Research, Practice and Policy 8: 222-232.

21. Marshall R, Olfson M, Hellman F, Blanco C, Guardino M (2001) Comorbidity, impairment, and suicidality in subthreshold PTSD. American Journal of Psychiatry 158: 1467-1473.

22. Scheeringa MS, Cohen JA (2009) Post-traumatic stress disorder diagnosis in children: challenges and promises. Dialogues Clinical Neuroscences 11: 91-99.

23. Schnurr PP, Friedman MJ, Rosenberg SD (1993) Premilitary MMPI scores as predictors of combat-related PTSD symptoms. American Journal of Psychiatry150: 479-483.

24. Stein MB, Walker JR, Hazen AL, Forde DR (1997) Full and partial posttraumatic stress disorder: Findings from a community survey. American Journal of Psychiatry 154: 1114-1119.

25. Scheeringa MS, Zeanah CH, Myers L, Putnam FW (2003) New findings on alternative criteria for PTSD in preschool children. Journal of American Academy Child and Adolescent Psychiatry 42: 561-570.

26. Jaycox LH, Stein BD, Kataoka SH, Wong M, Fink A (2002) Violence exposure posttraumatic stress disorder, and depressive symptoms among recent immigrant schoolchildren. Journal of the American Academy Of Child $y$ Adolescent Psychiatry 41: 1104-1110.

27. Jaycox LH, Langley AK, Stein BD, Wong M, Sharma $P$ (2009) Support for students exposed to trauma: A pilot Study. School Mental health 1: 49-60.

28. Friedman M, Resick P, Keane T (2007) Key question and an agenda for future research. Handbook of PTSD.

29. Asmundson GJG, Stapleton JA, Taylor S (2004) Are avoidance and numbing distinct PTSD symptom clusters. Journal of Traumatic Stress 17: 467-475.

30. Elhai JD, Palmieri PA (2011) The factor structure of posttraumatic stress disorder: a literature update, critique of methodology, and agenda for future research. Journal of Anxiety Disorders 25: 849-854.

31. Elhai JD, Biehn TL, Armour C, Klopper JJ, Frueh CB, et al. (2011) Evidence for a unique PTSD construct represented by PTSD's D1-D3 symptoms. Journal of Anxiety Disorders 25: 340-345

32. American Psychiatric Association (2013) Diagnostic and statistical manual of mental disorders Washington.

33. Armour C, Tsai J, Durham TA, Charak R, Biehn TL, et al. (2015) Dimensional structure of DSM-5 posttraumatic stress symptoms: support for a hybrid Anhedonia and Externalizing Behaviors model. Journal of Psychiartic Research 61: 106-113.

34. Brewin CR (2013) I wouldn't start from here an alternative perspective on PTSD from the ICD-11: comment on Friedman. Journal of Traumatic Stress 26: 557-559.

35. Cloitre M, Garvert DW, Brewin CR, Bryant RA, Maercker A (2013) Evidence for proposed ICD-11 PTSD and complex PTSD: A latent profile analysis. European Journal of Psychotraumatology 4: 1-12.

36. Gudiño OG, Rindlaub LA (2014) Psychometric properties of the Child PTSD Symptom Scale in Latino children. Journal Trauma Stress 27: 27-34.

37. Olliac B, Birmes P, Bui E, Allenou C, Brunet A (2014) Validation of the French Version of the Child Post-Traumatic Stress Reaction Index: Psychometric Properties in French Speaking School-Aged Children.

38. Rincón P, Gysling M, Jiménez C, Lloyd S, Navarro MF (2014) Propiedades 
psicométricas de la Escala de Síntomas de TEPT para niños (CPSS) en Población Chilena Afectada por el terremoto y Tsunami del 27-F de 2010 Terapia Psicológica 32: 57-64.

39. Uemoto M, Asakawa A, Takamiya S, Asakawa K, Inu A (2012) Kobe Earthquake and Post-Traumatic Stress in School-Aged Children. International Journal of Behavioral Medicine1: 243-251

40. Wherry JN, Huffhines LP, Walisky DN (2016) A Short Form of the Trauma Symptom Checklist for Children. Child Mal treatment 21: 37-46.

41. Gillihan SJ, Aderka IM, Conklin PH, Capaldi S, Foa E (2013) The Child PTSD Symptom Scale: Psychometric Properties in Female Adolescent Sexual Assault Survivors. Psychological Assessment 25: 23-31.

42. Kassam-Adams N, Marsac M, Cirilli C (2010) Posttraumatic Stress disorders symptom structure in injured children: Functional impairment and depression symptoms in a confirmatory factor analysis. Journal of the American Academy of Child Adolescent Psychiatry 49: 616-625.

43. King DW, Leskin GA, King LA, Weathers FW (1998) Confirmatory factor analysis of the clinician-administered PTSD Scale: evidence for the dimensionality of posttraumatic stress disorder. Psychological Assessment 10: 90-96.

44. Konecky B, Meyer EC, Kimbrel NA, Morissette SB (2015) The Structure of DSM-5 Posttraumatic Stress Disorder Symptoms in War Veterans. Anxiety, Stress, and Coping 14: 1-26.

45. Tsai J, Harpaz-Rotem I, Armour C, Southwick SM, Krystal JH (2015) Dimensional structure of DSM-5 posttraumatic stress disorder symptoms: results from the National Health and Resilience in Veterans Study. The Journal of clinical psychiatry $76: 5$ 546-553.

46. Stein DJ, McLaughlin KA, Koenen KC, Atwoli L (2014) DSM-5 and ICD-11 definitions of posttraumatic stress disorder: Investigating "narrow" and "broad" approaches. Depression and Anxiety 31: 494-505.

47. Wang L, Zhang L, Armour Ch, Cao Ch, Quing Y (2015) Assessing the underlying dimensionality of DSM-5 PTSD symptoms in Chinese adolescents surviving the 2008 Wenchuan earthquake. Journal of Anxiety Disorder 31: 90-97.

48. Wang Z, Baker DG, Harre J, Hammer M, Price M, et al. (2011) The Relationship between combat-realted posttraumatic Stress Disorder and the 5-HTTLPR/rs 25531 polimorphism. Depression and Anxiety 28: 1067-1073.

49. Fernández MV, López Soler C, López JA (2014) Maltrato infantil: Un estudio empírico sobre variables psicopatológicas en menores tutelados (Tesis doctoral). Departamento de Personalidad evaluación y tratamiento Psicológico. Facultad de Psicología. Universidad de Murcia.

50. Foa EB, Johnson KM, Feeny NC, Treadwell KR (2001) The Child PTSD Symptom Scale: A Preliminary Examination of its Psychometric Properties. Journal of Clinical Child Psychology 30: 376-384.

51. Wolfe VV, Gentile C, Michienzi T, Sas L, Wolfe D (1991) The Children's Impac of Traumatic events Scale-revised: A measure of postsexual abuse PTSD symptoms. Behavioral Assessment 14: 359-383.

52. Crouch JL, Smith DW, Ezzell CE, Saunders BE (1999) Measuring reactions to sexual trauma among children: Comparing the Children's Impact of Traumatic events Scale and the trauma Symptom Checklist for Children. Child Maltreatment 4: 225-263.

53. Horowitz M, Wilner N, Alvarez W (1979) Impact of Event Scale: A Measure of Subjective Stress. Psychosomatic Medicine 41: 209-218.

54. Saylor CF, Swenson CC, Reynolds SS, Taylor M (1999) The pediatric emotional distress scale: a brief screening measure for young children exposed to traumatic events. Journal of Clinical Child Psychology 28: 70-81.

55. Achenbach TM (1991) Manual for the Child Behavior. University of Vermont.

56. Lorenzo-Seva U, Ferrando P (2006) FACTOR: A computer program to fit the exploratory factor analysis model. Behavior Research Methods 38: 88-91.

57. Muris $\mathrm{P}$, Merckelbach H, Collaris R (1997) Common childhood fears and their origins. Behaviour Research and Therapy 35: 929-937.

58. Achenbach TM, Rescorla LA (2001) Manual for the ASEBA school-age forms \& profiles. Burlington: University of Vermont Research Center for Children.

59. American Psychiatric Association (2000) Diagnostic and statistical manual of mental disorders: DSM-IV-TR.
60. Báguena MJ, Villarroya E, Beleña A, Díaz A, Roldán C (2001) Psychometric Properties of the Spanish Version of the Revised Stressor Impact Scale. Análisis y Modificación de Conducta 27: 581-604.

61. Bremner JD, Vermetten E, Schmahl C, Vaccarino V, Vythilingam M (2005) Positron emission tomographic imaging of neural correlates of a fear acquisition and extinction paradigm in women with childhood sexual-abuse related posttraumatic stress disorder. Psychology Medicine 35: 791-806.

62. Castro M, López-Soler C, López JJ (2011) Trastorno por estrés postraumático en menores que han sufrido maltrato familiar directo y exposición a la violencia de género (Tesis doctoral). Departamento de Personalidad, Evaluación y Tratamiento Psicológico. Facultad de Psicología. Universidad de Murcia.

63. Cohen JA, Scheeringa MS (2009) Post-traumatic stress disorder diagnosis in children: challenges and promises. Dialogues Cliniques Neurosciences 11: 91 99.

64. Friedman MJ, Resick PA, Bryant RA, Brewin CR (2011) Considering PTSD for DSM-5. Depression and Anxiety 28: 750-769.

65. Kilpatrick DG, Acierno R, Saunders B (2000) Risk factors for adolescent substance abuse and dependence: data from a national sample. Journal of Consulting and Clinical Psychology 68: 19-30.

66. Liu P, Wang L, Cao C, Wang R, Zhang J (2014) The underlying dimensions of DSM-5 posttraumatic stress disorder symptoms in an epidemiological sample of Chinese earthquake survivors. Journal of Anxiety Disorders 28: 345-351.

67. Muris $P$, Merckelbach $H$, Körver $P$, Meesters C (2000) Screening for trauma in children and adolescents: the validity of the Traumatic Stress Disorder Scale of the screen for child anxiety related emotional disorders. Journal of Clinical Child Psychology 29: 406-413.

68. O'Donnell ML, Alkemade N, Nickerson A, Creamer M, McFarlane AC (2014) Impact of the diagnostic changes to post-traumatic stress disorder for DSM-5 and the proposed changes to ICD-11.

69. Organización Mundial de la Salud. CIE 10. Trastornos mentales y de comportamiento. Descripciones clínicas y pautas para el diagnóstico. Madrid: Mediator; 1992.

70. Organización Mundial de la Salud (2000) Guía de bolsillo de la clasificación CIE-10. Clasificación de los trastornos mentales y del comportamiento con glosario y criterios de investigación. Madrid: Panamericana.

71. Perry BD (2014) The cost of caring: Understanding and preventing secondary traumatic stress when working with traumatized and maltreated children. CTA Parent and Caregiver Education.

72. Pincus HA, Davis WW, McQueen LE (1999) Subthreshold mental disorders: a review and synthesis of studies on minor depression and other "brand names." British Journal of Psychiatry.

73. Roth SH, Newman E, Pekovitz D, van der Kolk BA, Mandel FS (1997) Complex PTSD in victims exposed to sexual and psysical abuse: Results from the DSMIV. Field Trial for Posttraumtic Stress Disorder. Journal of Traumatic Stress 10: $539-555$

74. Sack WH, Seeley JR, Clarke GN (1997) Does PTSD transcend cultural barriers? A study from the Khmer Adolescent Refugee Project. Journal of the American Academy of Child and Adolescent Psychiatry 36: 49-54.

75. Simms LJ, Watson D, Doebbelling BN (2002) Confirmatory factor analyses of posttraumatic stress symptoms in deployed and non-deployed veterans of the Gulf War. Journal of Abnormal Psychology 111: 637-647.

76. Tay K, Rees S, Chen J, Kareth M, Silove D (2015) The structure of posttraumatic stress disorder and complex post-traumatic stress disorder amongst West Papuan refugees. Alvin BMC Psychiatry 15: 111.

77. Teicher MH, Ito Y, Glod CA, Andersen SL, Dumont N, et al. (1997) Preliminary evidence for abnormal cortical development in physically and sexually abused children using EEG coherence and MRI. Annals of the New York Academy of Sciences 82: 160-175

78. Van Emmerik AA, Kamphuis JH (2011) Testing a DSM-5 reformulation of posttraumatic stress disorder: Impact on prevalence and comorbidity among treatment-seeking civilian trauma survivors. Journal of Traumatic Stress 24 213-217. 